\title{
Efficacy of Cognitive-Behavior Therapy (CBT) On Depressed Spouses of Cancer Patients in an Adjuvant Care Setting
}

\author{
S. MANTHIRAMOORTHIYA PILLAI
}

\begin{abstract}
Purpose: To assess the efficacy of cognitive behavior therapy for spouses of cancer patients with refractory depression according to the Diagnostic and Statistical Manual of Mental Disorders-IV.

Patients and Methods: All English-speaking spouses of cancer patients were eligible to participate. All spouses completed the following self-report questionnaires: Demographic variables sheet and Beck Depression Inventory (BDI). The research sample was consisted of 10 married spouses of cancer patients in the Adyar Cancer Institute, Chennai, in southern India. All spouses with moderate degrees of depression were selected. The cognitive behavior therapy sessions extended for 60 minutes and were held once weekly. The present study is a pre-post test design before and after intervention program. Continuous data were analyzed by using paired t tests to assess change over time. The analyses were conducted by using the SPSS version 11.0.

Results: The mean of the Beck scores at the beginning and end of the study was respectively: Intervention group 24.6, $S D=3.84$ versus $11.4, S D=4.27$ and control group $26.4, S D=4.21$ versus $27, S D=3.93$, the decrease in the Intervention group was significantly more than control group. Intervention group showed a significant decrease in BDI scores, $t(17.96)=4, p<.000$. However, there were no significant within control group change in BDI scores, $t(-o .557)=4, p>.607$.

Conclusion: Depression is common and persistent in spouses of cancer patients. Psychological screening and appropriate intervention such as CBT is an essential part of palliative care. This preliminary study suggested that cognitive behavior therapy might be an effective psychological treatment for major depression among spouses of cancer patients. However, further large scale randomized controlled trials are needed before definitive conclusions can be drawn.
\end{abstract}

\section{Introduction}

Cancer as severe illness creates a stressful situation for the entire family and affects each family member. Patients may become highly psychologically distressed and may perceive a low quality of life resulting from the fear of dying, a worsening physical condition, painful treatments, and side effects of such treatments.

Cancer is not the patient's problem alone. When a patient is hospitalized in south of India, he or she is often accompanied by a family member. In most cases, this family member will stay overnight at the hospital beside. For cancer patients the spouse is predominant primary caregiver. Spouses share many caregiving tasks, such as monitoring intravenous infusion, changing the patient's position, feeding, preparing foods, and etc. Unfortunately, spouses may not always be able to provide support that is helpful (Manne, Ostroff, Sherman et al.,2003; Pistrang, \& Barker,1995). At the same time, spouses may perceive anxiety, distress and depression because of losing their loved one, and because of possible burdens, such as the provision of care and support, and restrictions regarding their social life.

Also, major depression is the most common psychiatric disorder among cancer patients and is associated with decreased quality of life, significant deterioration in recreational and physical activities, relationship difficulties, sleep problems, more rapidly progressing cancer symptoms, and more metastasis and pain relative to non-depressed cancer patients. This diagnosis is even more common among patients with advanced cancer.

Approximately $16-25 \%$ of newly diagnosed cancer patients experience depression or an adjustment disorder with depressed mood (Sellick, \& Crooks, 1999). Depression has also been associated with functional limitations in cancer survivors (Wang, van Belle, JKukull \& Larson, 2002) and both anxiety and depression can independently contribute to functional and overall health (Dausch, Compas, Beckjord, Luecken, AndersonHanley, Sherman, \& Grossman, 2004; Simmonds, 2002). Effective long-term management of these problems remains a challenge (Kristeller, Zumbrun, \& Schilling, 1999).

The findings on distress in cancer patients and their partners are inconsistent. In several studies intimate partners were found to be as distressed as patients (e.g. Northouse and Swain, 1987; Oberst and Scott, 1988; Baider et al., 1996). In a study by Given and Given (1992), husbands of patients with recurrent breast cancer reported even more depressive symptoms than their wives. However, other studies among couples dealing with breast cancer showed lower levels of distress for the husbands than for the patients (Hoskins, 1995; Northouse et al., 1998). Another study among 133 couples (56\% with a male patient) dealing with 
similar types of cancer reported the lowest scores on psychological distress for husbands of patients (Baider et al., 1998a). Female partners perceived more distress than male partners (cf. Morse and Fife, 1998), whereas there was no gender difference among patients.

The studies that focus on both breast cancer patients and their spouses indicate divergent results when adjustment to the illness is assessed. Northouse and Swain's (1987) studies, showed no significant differences between patients and spouses in psychological distress (as assessed by the BSI). Hoskins' (1995) study, in contrast, indicated that breast cancer patients' psychological distress and their well-being were higher than their spouses'. Baider and Kaplan De-Nour (1988), however, found that spouses had more psychosocial problems than patients, and Gilbar et al. (1995), who studied patients with gynecological cancer and their spouses, showed that the spouses' psychological distress (as assessed by the BSI) was more severe than the patients'. A psychological disturbance such as depression in the partner has a detrimental effect on the patient. Hence, the main purpose of including the spouse in cognitive behavior therapy is to ameliorate depression in them.

Spouses often provide home care for their ill husband or wife (Given, Stommel, Given, Osuch, Kurtz, Kurtz, 1993; Miaskowski, Kragness, Dibble, Wallhagen, 1997). Although many spousal caregivers report high levels of depression, there is significant variability in depressive symptoms (Pinquart, Sörensen, 2003). For example, several studies have reported little mood disturbance and relatively low depression scores among caregivers of cancer outpatients (Given et al., 1993; Hagedoorn, Buunk, Kuijer, Wobbes, Sanderman, 2000), whereas others have shown that up to $30 \%$ of cancer caregivers have significant psychological distress (Williamson, Schulz, 1995; Ybema, Kuijer, Buunk, DeJong, Sanderman, 2001).Treating and preventing severe levels of depression in the spouses of individuals with cancer is important. Depression in caregivers may diminish the quality and quantity of home health care provided (Williamson, Shaffer, 2001), leading to impaired quality of life, physical morbidity, and premature mortality of the caregivers (Lebowitz, Pearson , Schneider, Reynolds, Alexopoulos, Bruce, Conwell, Katz, Meyers, Morrison, Mossey, Niederehe, Parmelee, 1997). Few studies have attempted to identify characteristics of spouses that make them more vulnerable to depression. Given that personality traits are associated with depression in spouses of patients with other cancers and chronic illnesses (Nijboer, Tempelaar, Triemstra, van den Bos, Sanderman, 2001; Hooker, Monahan, Bowman, Frazier, Shifren, 1998; Bookwala, Schulz, 1998; Patrick \& Hayden, 1999; Zanetti, Frisoni, Bianchetti, Tamanza, Cigoli, Trabucchi, 1998; Ell, Nishimoto, Mantell, Hamovitch, 1998), it is possible that spouses who are at risk for depression can be identified on the basis of their personality traits.

There is evidence of deterioration of marital relationship in a substantial minority of patients. A common cause of such deterioration is lack of communication between the patient and spouse or partner (Lichtman \& Taylore 1986). In a study of couples where the woman was newly diagnosed with breast cancer, Hillton (1994) identified three main patterns of discussion about fears and doubts. In the first the couple were in agreement that talking openly was the best policy, in the second couples agreed not to discuss the illness with each other, and in the third the two partners held differing views about talking openly about their feelings.It was last group which demonstrated more problems in their communication. Selective open disclosure was perceived as the most satisfactory of the patterns.

Since Beck first introduced cognitive behavior therapy (CBT) for depression (1967; Beck, Rush, Shaw \& Emery, 1979), there have been numerous studies demonstrating its efficacy (Dobson, 1989; Evans et al., 1992; Hollon, Evans, \& DeRubeis, 1990; Jacobson, and Hollon, 1996). Beck's CBT is based on the underlying theoretical rationale that an individual's emotions, motivations, and behavior are largely determined by the way in which he or she constructs the world. Subjective thoughts, images, and feelings are rooted in the enduring attitudes and assumptions, or schemas, which the individual develops from prior experience. Human experience is automatically filtered through these cognitive structures, by which input is categorized and evaluated.

Cognitive behavior therapy (CBT) for depression is conducted within a framework of collaborative empiricism. The therapist assumes an active, directed stance, joining with the client in a logical and empirical investigation of the client's beliefs, attitudes, inferences, and assumptions.

Therapy focuses on the present, examining the client's thoughts and feelings as they occur during the session as well as in the client's everyday life. Therapist and client work together to establish specific treatment goals designed to ameliorate depressive symptoms and any other problems that they agree to address.

Most studies have used heterogeneous groups of patients, so it is not yet possible to make judgments about which types of cancer CBT may or may not work with. Definite evidence exits for efficacy with breast cancer (Edelman et al. 1999a) and malignant melanoma (Fawzy et al. 1996). The single study with testicular cancer failed to find an effect (Moynihan et al. 1998). There is no evidence to suggest that people with metastatic or more advanced disease do less well with CBT than people with early cancer.

Finally, among male partners of cancer patients, we expected that there will be no significant difference in depression of spouses before and after Cognitive Behavior Therapy in the control group (Hypothesis 1). 
Efficacy of Cognitive-Behavior Therapy (CBT) on Depressed Spouses of Cancer Patients in an

Furthermore, it was expected that there will be no significant difference in depression of spouses before and after Cognitive Behavior Therapy in the experimental group (Hypothesis 2). Finally, there will be no significant difference in depression before and after Cognitive Behavior Therapy between control and experimental groups.

\section{Participants}

\section{Method}

All English-speaking spouses of patients who had been diagnosed with and treated for breast, colorectal and lung cancer within the last 2 years were eligible to participate. The research sample was consisted of 10 married spouses of patients with breast, colorectal and lung cancers in the Adyar Cancer Institute, Chennai, in southern India.

The experimental group's mean age was 55.2 years $(\mathrm{SD}=12.11$ years, range $=46-76$ years), and the control group's mean age was 51 years $(\mathrm{SD}=8.8$ years, range $=38-62$ years). Mean number of formal education was 11.2 $(\mathrm{SD}=6.72$, range $=0-21)$ for spouses in experimental group and $9.4(\mathrm{SD}=7.7$, range $=0$ - 21) for spouses in control group. Average number of children was 2.4 (1.14) for experimental group and 2.2 (0.83) for control group. Forty percent of spouses in experimental group and $80 \%$ of the spouses in control group were employed during the interview period.

\section{Measures}

A brief questionnaire included items covering demographic characteristics (age, education, occupation, income, residence, number of children and religion) and other descriptive variables (e.g., stage of wife's cancer).

Beck Depression Inventory, BDI (Beck \& Beamesderfer,1974). A measure of depressive symptoms was provided by the BDI. The Beck Depression Inventory created by Aaron T. Beck, is a 21-question multiplechoice self-report inventory that is one of the most widely used instruments for measuring the severity of depression. The BDI is a self-administered depressive scale measuring the extent of depressive symptoms such as hopelessness and irritability, cognitions such as guilt or feelings of being punished, as well as physical symptoms such as fatigue, weight loss, and lack of interest in sex.

\section{Procedures}

Ten spouses of cancer patients fulfilled the inclusion criteria and were recruited for the study after providing informed consent. Their wives were in treatment for cancer or visiting the surgeon for check-up. All spouses completed the following self-report questionnaires: Demographic variables sheet and Beck Depression Inventory (BDI). As cognitive behavior therapy was provided solely by the first author, there was a mean delay of approximately 2 months before spouses could start therapy. At commencement of cognitive behavior therapy, all participants were required to repeat of the self-report questionnaires to confirm the stability of the symptoms.

Beck Depression Inventory (BDI) was completed weekly by the participants to assess their response to the intervention. For the purpose of this study, only the data from the last session were used for analysis.

\section{Cognitive Behavior Therapy (CBT)}

The main goals for CBT treatment are to reduce depressive symptoms and the length of time the spouse is depressed, teach ways to prevent becoming depressed, feel more in control of their lives. The cognitive behavior therapy sessions extended for 60 minutes and were held once weekly. The therapist had experience and training in cognitive behavior therapy for depression. The treatment provided was based on the cognitive behavior therapy manual on depression (Munoz, Miranda, 2000).The therapist taught participants to identify and evaluate key negative automatic thoughts and applied schema restructuring techniques to dispute core beliefs and to develop more adaptive beliefs and behavior. Special attention was given to the development of a collaborative and trusting therapeutic alliance with the participants. Where appropriate, some modification in cognitive behavior therapy techniques was made in order to enhance acceptability for Indian patients.

\section{Statistical Analysis}

The present study is a pre-post test design before and after intervention program. Continuous data were analyzed by using paired $t$ tests to assess change over time. The $\mathrm{p}$ value was set at 0.05 . The analyses were conducted by using the Statistical Package for Social Sciences version 11.0.

\section{Results}


Intervention Group vs. Waiting List Control Group at baseline. No significant differences emerged among the baseline scores on demographic and symptom the measures between intervention group $(\mathrm{N}=5)$ and control group $(\mathrm{N}=5)$.

Of the 8 patients who were randomly assigned to treatment, $5(62.5 \%)$ completed the 12 weeks of treatment and $3(37.5 \%)$ discontinued participation prematurely. Only 1 patient withdrew because of assignment to the control group. No differences of more than $15 \%$ were seen between dropouts and completers on any of the measured demographic, depression, and clinical characteristics (age, marital status, education, previous episodes and treatment of depression) and BDI scores before treatment.

The mean of the Beck scores at the beginning and end of the study was respectively: Intervention group 24.6, $\mathrm{SD}=3.84$ versus $11.4, \mathrm{SD}=4.27$ and control group $26.4, \mathrm{SD}=4.21$ versus $27, \mathrm{SD}=3.93$, the decrease in the Intervention group was significantly more than control group. The cognitive behavior therapy method decreased significantly the mean of the Beck scores more than the control group (Figure 1).

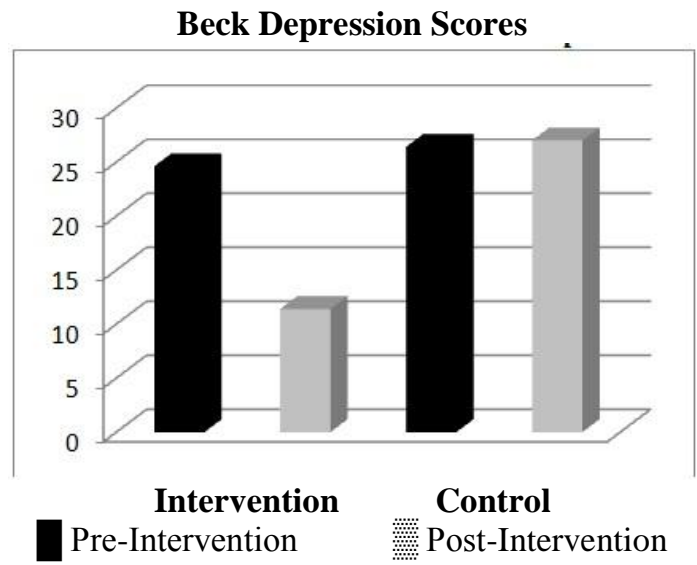

Figure 1.Effects of Intervention vs. waiting-list control on depression.

The percentage of patients achieving remission of depression (Beck Depression Inventory score $\leq 15$ ) was greater in the CBT group than in the control group: post-treatment, $80.0 \%$ of patients in the CBT group (4 of 5) compared with $00.0 \%$ of controls ( 0 of 5) unachieved remission (difference, 80.0 percentage points).

Post-intervention results were analyzed with paired $t$ tests. The within Intervention group change in BDI scores was analyzed using paired $t$ tests. Intervention group showed a significant decrease in BDI scores, $t(17.96)=4$, $\mathrm{p}<.000$. However, there were no significant within control group change in BDI scores, $t(-0.557)=4, p>.607$. There were no significant differences between the scores of Beck depression in Intervention group and control group.

Depression outcomes were further studied by using a paired $t$ tests transformed BDI scores. Reduction in depression symptoms was greater, at post-treatment and evaluations, in the CBT group than in the control group $(P<0.000$ for post-treatment).

\section{Discussion}

Family caregivers have received very little attention in published literature from India. This is surprising as the family forms the backbone of support in a collectivistic society like India with limitations in terms of availability of tertiary supports. Also, studies test the feasibility and efficacy of various psychological interventions for cancer patients are scarce (Mehrotra, 2008). This is the first reported study of cognitive behavior therapy for depression of spouses of cancer patients in India. This was intended to be a pilot study to stimulate further interest in investigating the effectiveness of psychotherapy for spouses of Indian people with cancer.

The efficacy of cognitive therapy for depressive disorder has been well documented (Gloaguen, Cottraux, Cucherat, \& Blackburn, 1998). The value of combining cognitive behavior therapy with antidepressants for improving response rate for chronically depressed patients has also been confirmed in a recent multicenter trial (Keller, McCullough, Klein, et al., 2000). The improvements in depressive symptoms in this study were therefore not surprising.

Our findings showed that, there are three adjuvant cares which have useful influences on quality of life and reduction of depression symptoms among cancer patients and their spouses. In the first, it is essential to encourage each partner to express freely all feelings including anger, fear, and sadness. Having learned how the patient really feels, the spouse is then encouraged in the same way to express feelings openly. The patient is often surprised to find that behind the spouse's cheerful façade there is anxious concern and sadness. This discovery can be a proof to the patient of how much the spouse cares. In the second, some couples, however, 
may not have been very good at talking even before the illness struck. In this case, both partners need to practice listening as well as expressing their feelings within the therapy session. Listening and empathic communication in this way it usually allows the couples to share their doubts and fears constructively. The partner who is listening is instructed to ask questions so that they get as clear an understanding as possible of what their partner is experiencing (tuning in to their wavelength). They are shown how to reflect empathically back through non-verbal gestures, through repeating and paraphrasing the partners words (thought empathy) and through feeding back what they understand of their partner's feelings (feeling empathy). Communication training of this kind can be particularly helpful for the spouse of the cancer patient who may be tempted to control, undermine, or invalidate the patient's experience, often for the best possible reasons. In the third, as a result, the spouse may show discrepancies between word and deed, encouraging the patient verbally while at the same time avoiding any discussion about cancer or even avoiding the patient. The effect on the patient is likely to be a sense of rejection and loss of self-esteem. In order to regain the spouse's sympathy and love, the patient may then attempt to suppress all negative feelings associated with cancer.

This was a pilot study with several methodological flaws. The sample size was small $(n=10)$. The participants were referred by oncologists so patients more suited to psychotherapy might have been preferentially selected. The treatment was a provided by a single therapist in a single center, raising doubt as to the generalisability of the findings. The lack of comparable psychotherapy for directed comparison was another drawback of this study. This pilot study was conducted to stimulate further enquiry into the effectiveness of cognitive behavior therapy for depression of spouses of cancer patients. Further large-scale randomized controlled trials are needed before definitive conclusions can be drawn about the efficacy of cognitive behavior therapy for depression among cancer caregivers.

Our study shows that CBT is an effective non-pharmacologic treatment for major depression in spouses of patients with cancer.

\section{References}

[1]. Manne S, Ostroff J, Sherman M et al. Buffering effects of family and friend support on associations between partner unsupportive behaviors and coping among women with breast cancer. J Soc Pers Relat 2003; 20:771-792.

[2]. Pistrang N, Barker C. A partner relationship in psychological response to breast cancer. Soc Sci Med 1995; 40: $789-797$.

[3]. Sellick S, Crooks D. Depression and cancer: An appraisal of the literature for prevalence, detection, and practice guideline development for psychological interventions. Psycho-Oncology 1999; 8:315-333.

[4]. Wang L, van Belle G, JKukull WB, Larson EB, Predictors of functional change: A longitudinal study of nondemented people aged 65 and older. Journal of the American Geriatric Society 2002; 50 (9): 1525-1534.

[5]. Dausch BM, Compas BE, Beckjord E, Luecken L, Anderson-Hanley C, Sherman M, Grossman C. Rates and correlates of DSM-IV diagnoses in women newly diagnosed with breast cancer. Journal of Clinical Psychological Medical Settings 2004; 11(3): 159-169.

[6]. Simmonds MJ. Physical function in patients with cancer: Psychometric characteristics and clinical usefulness of a physical performance test battery. Journal of Pain Symptom Management 2002; 24 (4): 404-414.

[7]. Kristeller JL, Zumbrun CS, Schilling RF. 'I would if I could': How oncologists and oncology nurses address spiritual distress in cancer patients. Psycho-Oncology 1999; 8(5): 451-458.

[8]. Northouse LL, Swain MA. Adjustment of patients and husbands to the initial impact of breast cancer. Nurs Res 1987; 36: 221-225.

[9]. Oberst MT, Scott DW. Post-discharge distress in surgically treated cancer patients and their spouses. Res Nurs Health 1988; 11: 223-233.

[10]. Baider L, Kaufman B, Peretz T, Manor O, Ever-Hadani P, Kaplan De-Nour A. Mutuality of fate: adaptation and psychological distress in cancer patients and their partners. In Cancer in the Family, Baider L, Cooper CL, Kaplan De-Nour A (eds). Wiley: Chichester 1996; 173-186.

[11]. Given B, Given CW. Patients and family caregiver reaction to new and recurrent breast cancer. J Am Med Women's Ass 1992; 47: 201-206.

[12]. Hoskins CN. Adjustment to breast cancer in couples. Psychol Reports 1995; 77: 435-454.

[13]. Northouse LL, Templin T, Mood D, Oberst M. Couples' adjustment to breast cancer and benign breast disease: a longitudinal analysis. Psycho-Oncology 1998; 7: 37-48.

[14]. Baider L, Koch U, Esacson R, Kaplan De-Nour A. Prospective study of cancer patients and their spouses: the weakness of marital strength. Psycho-Oncology 1998a; 7: 49-56.

[15]. Morse SR, Fife B. Coping with a partner's cancer: adjustment at four stages of the illness trajectory. Oncol Nurs Forum 1998; 25: 751-760.

[16]. Baider L, Kaplan De-Nour A. Breast cancer - a family affair. In: Cooper C, editor. Stress and breast cancer. New York: Wiley; 1988. P. 155-170.

[17]. Gilber O, Steiner M, Atad J. Adjustment of married couples and unmarried women to gynaecological cancer. Psycho-Oncology 1995; 4:203-11.

[18]. Beck A.T. Depression: Clinical, experimental, and theoretical aspects. New York: Hoeber; 1967.

[19]. Beck A.T., Rush, A.J., Shaw, B.F., \& Emery, G. Cognitive therapy of depression. New York: Guilford Press; 1979.

[20]. Beck A.T., Beamesderfer A. Assessment of depression: the depression inventory. Mod Probl Pharmacopsychiatry. 1974; 7:151-69.

[21]. Dobson, K.S. A meta-analysis of the efficacy of cognitive-behavioral therapy for depression. Journal of consulting and clinical psychology 1989; 57:414-419.

[22]. Evans, M.D., Hollon, S.D., DeRubeis, R.J., Piasecki, J.M., Grove, W.M., Garvey, M.J.,\& Tuason, V.B. Differential relapse following cognitive therapy and pharmacotherapy for depression. Archives of General Psychiatry 1992; 49: 802-808.

[23]. Hollon, S.D., Evans, M.D, \& DeRubeis, R.J. Cognitive mediation of reapse prevention following treatment for depression: Implications of differential risk. In R.E. Ingram (Ed.), Contemporary psychological approaches to depression (pp. 117-136). New York: Guilford Press; 1990.

[24]. Jacobson, N.S., \& Hollon, S.D. cognitive behavior therapy and pharmacotherapy: Now that the jury's returned its verdict, it's time to present the rest of the evidence. Journal of Consulting and Clinical Psychology 1996; 64: 74-80. 
[25]. Gloaguen V, Cottraux J, Cucherat M, Blackburn I. A meta-analysis of the effects of cognitive therapy in depressed patients. $J$ Affect Dis 1998; 49:59-72.

[26]. Keller M, McCullough J, Klein D, et al. A comparison of nefazadone, the cognitive behavioral analysis system of psychotherapy, and their combination for the treatment of chronic depression. N Engl J Med 2000; 342: 1462-1470.

[27]. Lichman, R.R. and Taylor, S.E. Close relationships and the female cancer patient. In Anderson, B.L. (ed.) Women with Cancer. New York: Springer 1986; PP.233-256.

[28]. Hilton, B.A. Family communication patterns in coping with early breast cancer. Western Journal of Nursing Research 1994; 16 : 366-388.

[29]. Edelman, S., Lemon, J., Bell, D.R, et al. Effects of group CBT on the survival time of patients with metastatic breast cancer. Psycho-Oncology 1999a; 8:471-481.

[30]. Fawzy, F.I., Fawzy, N.W., and Wheeler, J.G. Apost-hoc comparison of the efficacy of a psychoeducational intervention for melanoma patients delivered in group versus individual formats: an analysis of data from two studies. Psycho-Oncology 1996; 5: 81-89.

[31]. Moynihan, C., Bliss, J.M., Davidson, J., et al. Evaluation of Adjuvant Psychological Therapy in Patients with testicular cancer: a randomized trial. British Medical Journal 1998; 316: 429-435.

[32]. Mehrotra, S. Psycho-Oncology research in India: Current status and future directions. Journal of the Indian Academy of Applied Psychology 2008; 34:7-18.

[33]. Given CW, Stommel M, Given B, Osuch J, Kurtz ME, Kurtz JC: The influence of cancer patients' symptoms and functional states on patients' depression and family caregivers' reaction and depression. Health Psychol 1993; 12:277-285[CrossRef][Medline]

[34]. Miaskowski C, Kragness L, Dibble S, Wallhagen M: Differences in mood states, health status, and caregiver strain between family caregivers of oncology outpatients with and without cancer-related pain. J Pain Symptom Manage 1997; 13:138147[CrossRef][Medline]

[35]. Pinquart M, Sörensen S: Differences between caregivers and noncaregivers in psychological health and physical health: a metaanalysis. Psychol Aging 2003; 18:250-267[CrossRef][Medline]

[36]. Hagedoorn M, Buunk BP, Kuijer RG, Wobbes T, Sanderman R: Couples dealing with cancer: role and gender differences regarding psychological distress and quality of life. Psycho-Oncology 2000; 9:232-242[CrossRef][Medline]

[37]. Williamson GM, Schulz R: Caring for a family member with cancer: past communal behavior and affective reactions. $J$ Applied Soc Psychol 1995; 25:93-116

[38]. Ybema JF, Kuijer RG, Buunk BP, DeJong GM, Sanderman R: Depression and perceptions of inequity among couples facing cancer. Pers Soc Psychol Rev 2001; 27:3-13

[39]. Williamson GM, Shaffer DR: Relationship quality and potentially harmful behaviors by spousal caregivers: how we were then, how we are now. Psychol Aging 2001; 16:217-226[CrossRef][Medline]

[40]. Lebowitz BD, Pearson JL, Schneider LS, Reynolds CF 3rd, Alexopoulos GS, Bruce ML, Conwell Y, Katz IR, Meyers BS, Morrison MF, Mossey J, Niederehe G, Parmelee P: Diagnosis and treatment of depression in late life: consensus statement update. JAMA 1997; 278:1186-1190[Abstract/Free Full Text]

[41]. Nijboer C, Tempelaar R, Triemstra M, van den Bos GAM, Sanderman R: The role of social and psychologic resources in caregiving of cancer patients. Cancer 2001; 91:1029-1039[CrossRef][Medline]

[42]. Hooker K, Monahan DJ, Bowman SR, Frazier LD, Shifren K: Personality counts for a lot: predictors of mental and physical health of spouse caregivers in two disease groups. J Gerontol B Psychol Sci Soc Sci 1998; 53B:73-85

[43]. Bookwala J, Schulz R: The role of neuroticism and mastery in spouse caregivers' assessment of and response to a contextual stressor. J Gerontol B Psychol Sci Soc Sci 1998; 53B:155-164

[44]. Patrick JH, Hayden JM: Neuroticism, coping strategies, and negative well-being among caregivers. Psychol Aging 1999; 14:273283[CrossRef][Medline]

[45]. Zanetti O, Frisoni GB, Bianchetti A, Tamanza G, Cigoli V, Trabucchi M: Depressive symptoms of Alzheimer caregivers are mainly due to personal rather than patient factors. Int J Geriatr Psychiatry 1998; 13:358-367[CrossRef][Medline]

[46]. Ell K, Nishimoto RH, Mantell JE, Hamovitch M: Psychological adaptation to cancer: a comparison among patients, spouses, and non-spouses. Family Systems Medicine 1988; 6:335-348

[47]. Munoz RF, Miranda J: Individual therapy manual for cognitive-behavioral treatment of depression. RAND 2000 